\title{
Electrorheological Properties of Phosphoric Ester Cellulose Electrorheological Suspensions with Activation of Dispersed Particles
}

\author{
Byeng-Gil AHN \\ Textile-Ceramic Hybrids Lab., New Functional Materials Research Department, Korea Institute \\ of Ceramic Engineering \& Technology, 233-5, Gasan-Dong, \\ Guemcheon-Gu, Seoul 153-801, KOREA
}

(Received January 28, 2002; Accepted October 4, 2002)

\begin{abstract}
The electrorheological (ER) behavior of activated ER suspensions in silicone oil of phosphoric ester cellulose powder (average particle size : $17.77 \mu \mathrm{m}$ ) was investigated at room temperature with electric fields up to $2.5 \mathrm{kV} \mathrm{mm}^{-1}$. For increasing ER effect of ER suspensions, activating effect of dispersed particles, phosphoric ester cellulose, on ER activity was studied. Anhydrous ER suspensions based on phosphoric ester cellulose particles made from cellulose treated in chemical solution of $2 \mathrm{M}$ phosphoric acid and $4 \mathrm{M}$ urea, heated at $150^{\circ} \mathrm{C}$ and crushed were measured. After activating the dispersed particles in anhydrous ER suspensions at $120^{\circ} \mathrm{C}$, analysis of the dispersed phosphoric ester cellulose particles was made. ER properties of ER suspensions such as dielectric constant, current density, electrical conductivity, and rheological properties were studied. Activating of dispersed particles had large influence on ER activities of anhydrous ER suspensions based on phosphoric ester cellulose. With activation time, particle size, and number of dispersed particles per unit volume, electrical properties, dynamic yield stress on electric field, initial apparent viscosity $\left(\eta_{0}\right)$, and ER effect $\left(\tau_{\mathrm{A}} / \tau_{0}\right)$ of phosphoric ester cellulose ER suspensions increased at $120^{\circ} \mathrm{C}$.

KEY WORDS Activating of Dispersed Particles / Activation Time / Electrorheological Property / Electrorheological Activity /
\end{abstract}

Electrorheological (ER) effects, defined as instantaneous reversible changes in apparent viscosity $\left[\eta_{0}\right]$ when a fluid is subjected to an external electric field, were reported as early as 1896 by Duff. ${ }^{1}$ He observed small variations in viscosities on glycerin, castor oil and a heavy paraffin due to an applied electric field. In 1949, Winslow reported large, reversible ER effects for certain suspensions of solids in dielectric liquids. Orders-of-magnitude increase in viscosity under the application of the electric field was observed. He attributed these large ER effects to induced chain-like structures of the particles. ER effect is generally known as the Winslow effect. ${ }^{2}$

Since Winslow's discovery fifty-three years ago, researchers have observed dramatic rheological changes in two-phase systems subjected to electric fields. Proposed ER devices range from the simple hydraulic valve $^{2}$ to the complex tracking device for copying machines. ${ }^{3}$ The principal attraction of ER suspension devices is their fast response time. This feature makes possible feedback control systems for robotics and automotive applications. The cornerstone of ER technology has been the electrorheological valve and resultant devices. In the valve ER suspension is pumped through a channel capacitor wherein the voltage difference between the walls may be varied to regulate flow resistance $\eta$ up to the point where the fluid solidifies and flow ceases.
The ER clutch, first patented by Winslow, ${ }^{2}$ has received the greatest attention in the automotive industries. ${ }^{4,5}$ A mechanical rotary transducer operates on the same principle of rapid solidification and has been described by Stangroom. ${ }^{6}$ Of additional interest to the automotive industry are variable damping devices based on ER suspensions. Shock absorbers, ${ }^{7,8}$ and tunable isolator ${ }^{9}$ have been designed.

While ER suspensions have been acclaimed as 'smart fluids', there are substantial limitations in ER technology which must be overcome before their full potential is recognized such as limited temperature range, especially water-activated systems. Hence, the search for fully anhydrous ER suspensions is ongoing. Another design consideration is the power requirement. Most favorable conditions correspond to low conductivity and high ER activity at low voltage. Because current passage is non-ohmic, the power requirement becomes increasingly more onerous as higher voltages are required to induce the desired ER effect.

ER devices should thus be evaluated realistically. Feasibility analysis has been conducted for ER devices in automotive applications using constitutive equations of basic ER suspension phenomena. ${ }^{10}$ A clutch with even the most effective ER suspension may require unreasonable dimensions $(0.5 \times 0.5 \mathrm{~m}$ or $0.1 \times 14 \mathrm{~m})$ to provide sufficient torque for automotive use. Power consumption for such a clutch would be in excess 
$(1800 \mathrm{~W})$. Thus, two feasible automotive applications for ER suspension are limited to shock absorbers and engine mounts. The greatest promise in realizing the full potential of ER effect is in the development of new ER suspension showing very fast response and high yield stress to the electric field. At constant volume fraction of dispersed particles, how can the ER effect of ER suspensions on the electric fields be enhanced?

A number of researchers have worked the ER effect of ER suspensions on dispersed inorganic particle size for increasing ER activity under constant volume fraction of dispersed particles. The sizes for ER suspensions particulates range from 0.04 to $50 \mu \mathrm{m}^{2,11-13}$ For very small particles, forces arising from Brownian motion compete with electrical forces inducing the ER effect. ${ }^{14}$ Very large particles would respond too slowly to an electric field for practical application in ER devices. ER properties of anhydrous ER suspension on the activation of organic dispersed particles, phosphoric ester cellulose, were investigated. At $120^{\circ} \mathrm{C}$, the swelling of dispersed organic particles was very useful to increase ER activity to the electric fields without changing the volume fraction of dispersed particles.

For study of the ER effect increase under constant volume fraction of dispersed organic particles, anhydrous ER suspensions with phosphoric ester cellulose particles dispersed in silicone oil $(50 \mathrm{cS})$ was designed. To enhance ER effect on the electric fields, the activating effect of dispersed organic particles on the ER activities was studied. With activation time, average particle size and number distribution of dispersed organic particles per unit ER suspension volume, electrical properties and initial apparent viscosity $\left(\eta_{0}\right)$ of ER suspensions increased.

\section{EXPERIMENTAL}

\section{Preparation of Anhydrous ER Suspensions}

Synthesis of Phosphoric Ester Cellulose Particles. Water solutions with $2 \mathrm{M}$ of phosphoric acid (85\% orthophosphoric acid) containing $4 \mathrm{M}$ of urea were made and stirred for half an hour at room temperature for uniformity of solution, and ammonium phosphate was generated by reaction of phosphoric acid and urea. Raw cellulose particles (Sigmacell, Sigma Chemical Co., average particle size $20 \mu \mathrm{m}$ ) were introduced into the ammonium phosphate solution and maintained at room temperature for $24 \mathrm{~h}$.

At $24 \mathrm{~h}$, the cellulose particles were separated from the ammonium phosphate solution by filtering and placed in an electrical furnace for phosphoric ester reactions of cellulose particles. ${ }^{15}$ After maintaining $2 \mathrm{~h}$ at $80^{\circ} \mathrm{C}$, the furnace temperature was increased to $150^{\circ} \mathrm{C}$ and maintained for $2 \mathrm{~h}$. The phosphoric ester cellulose particles ${ }^{15}$ made from phosphoric ester reaction of cellulose were neutralized by $5-6$ washings with distilled water.

Preparation of Phosphoric Ester Cellulose ER Suspensions. Dried phosphoric ester cellulose particles were mixed with anhydrous $50 \mathrm{cS}$ silicone oil (ShinEtsu Silicone Co., Japan) prepared by exposing oil to molecular sieves for one week. ER suspensions were made by mixing $20 \mathrm{vol} \%$ of phosphoric ester cellulose particles and $80 \mathrm{vol} \%$ of silicone oil with the ball-mill for $24 \mathrm{~h}$ for uniform dispersion of the fine particles into the silicone oil.

Activating of Phosphoric Ester Cellulose ER Suspensions. Anhydrous ER suspension made by mixing $50 \mathrm{cS}$ silicone oil ( $80 \mathrm{vol} \%$ ) and phosphoric ester cellulose particles $(20 \mathrm{vol} \%)$ was activated at constant volume fraction of dispersed particles. The system was stirred for $9 \mathrm{~h}$ at $120^{\circ} \mathrm{C}$ for activating the dispersed phosphoric ester cellulose particles. During activation, an ER suspension specimen was taken every hour to observe volume fraction variation.

For measuring volume fraction variation before and after the activating of ER suspension, an ER suspension was taken a every activating hour and density of dispersed solid particles was measured by Pycnometer. After mixing the $n$-hexane solvent $(500 \mathrm{~mL})$ to a very small quantity of activated ER suspension, the diluted solution was filtered with $0.47 \mu \mathrm{m}$ pore size membrane filter element for measuring the density of dispersed solid particles in activated ER suspensions after removing the solvent at vacuum oven. Volume fraction behavior of dispersed ER particles before and after the activating was investigated.

\section{Characterization of Activated ER Suspensions}

Electrical Measurement. Dielectric and conductive properties of the activated phosphoric ester cellulose ER suspensions were measured with variation in activation time at $120^{\circ} \mathrm{C}$. The arrangement of dispersed particles (i.e., chain formation) influences the electrical properties of the fluids (Miller and Jones, 1988), ${ }^{16}$ and thus the following method was used to obtain dielectric properties of ER suspensions and experiment was performed at room temperature on a DC bias LCR meter (Hewlett Packard, HP 4263B, U. S. A.). Dielectric constants were calculated by capacitance ${ }^{17}$ of ER suspensions. DC conductivity determined by measuring the current on the high electric field conditions. ER suspension specimen was held in an aluminum cup, whose outer diameter, inner diameter and height were $40 \mathrm{~mm}$, $38 \mathrm{~mm}$, and $50 \mathrm{~mm}$, respectively, with a flat bottom made by plastic. Electrode area for calculating elec- 
trical properties was $59.69 \mathrm{~cm}^{2}$ and regular thickness, $1 \mathrm{~mm}$. Data were collected, after the ER suspension was initially stirred at $E=0$, and immediately checked up to $4.5 \mathrm{kV} \mathrm{mm}^{-1}$.

The equation of current density $\left(j_{\mathrm{f}}\right)$ is

$$
j_{\mathrm{f}}=\frac{I_{\mathrm{f}}}{A}
$$

and conductivity $\left(\sigma_{\mathrm{f}}\right)$ of the ER suspension was calculated as following

$$
\sigma_{f}=\frac{\Delta j_{\mathrm{f}}}{\Delta E}
$$

where A is electrode area in contact with the ER suspension, $I_{\mathrm{f}}$ current under constant electric field and $E$ electric field.

Rheological Measurement. Shear stress-strain rate data for ER suspensions were obtained using a viscometer. High voltage was supplied with a Keithley High Voltage Supplier (Model 248, U. S. A.) connected to the cup and bob of Couette type viscometer by a thin wire. Data were obtained for strain rate up to $110 \mathrm{~s}^{-1}$ at room temperature. Rheological behavior of the phosphoric ester cellulose ER suspensions was studied with variation in activation time at $120^{\circ} \mathrm{C}$.

For ER suspensions, electrorheological effect (ER effect, $\eta_{\mathrm{R}}$ or $\tau_{\mathrm{R}}, \eta_{\mathrm{R}}=\eta_{\mathrm{A}} / \eta_{0}$ or $\left.\tau_{\mathrm{R}}=\tau_{\mathrm{A}} / \tau_{0}\right)$ is very important for application of real mechanical parts, where $\eta_{\mathrm{A}}$ (or $\tau_{\mathrm{A}}$ ) and $\eta_{0}$ (or $\tau_{0}$ ) stand for the apparent viscosity (or shear stress) with and without an electric field, respectively.

\section{RESULTS AND DISCUSSION}

Analysis of Activated Phosphoric Ester Cellulose Particles

Before activating at $120^{\circ} \mathrm{C}$, the density of phosphoric ester cellulose pure particles, $1.31 \pm 0.05 \mathrm{~g} \mathrm{~cm}^{-3},{ }^{15}$ was measured by a Pycnometer.

Particle size of phosphoric ester cellulose particles was controlled a sieve shaker (passing $26 \mu \mathrm{m}$ sieve). The particles were dried in a vacuum at $100^{\circ} \mathrm{C}$ oven for $48 \mathrm{~h}$. Particle size distribution measured by Image Analyzer System (Model Omnimet 2, UK) and mean particle size was $17.77 \mu \mathrm{m} .{ }^{18}$ Phosphoric ester cellulose particles dispersed into silicone oil were stable below $200^{\circ} \mathrm{C}$ proving that ER suspensions based on phosphoric ester cellulose were anhydrous. ${ }^{15,18}$

During activation at $120^{\circ} \mathrm{C}$, the density of dispersed solid particles was measured every activating hour. Initial density and volume fraction of dispersed ER particles, $1.31 \pm 0.05 \mathrm{~g} \mathrm{~cm}^{-3}$ and $20 \%$, were hardly changed during the activation.

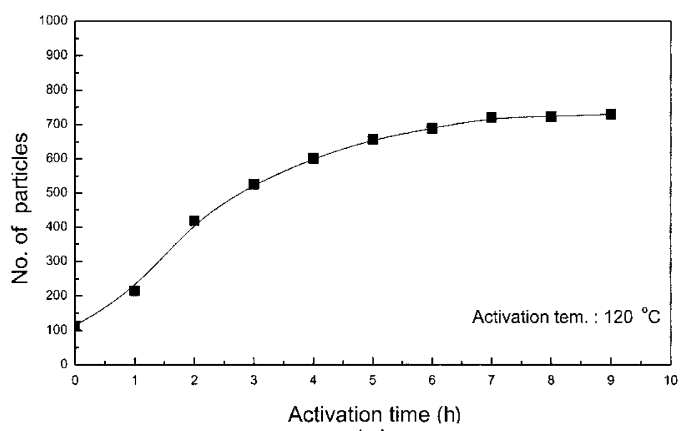

(a)

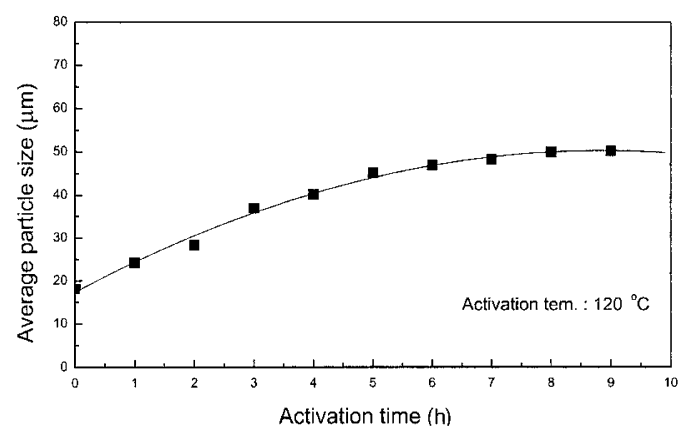

(b)

Figure 1. Effects of activation time on number of particles and average particle size. (a) No. of particles vs. activation time. (b) Average particle size $v s$. activation time.

Average particle size and number distribution of dispersed particles per unit volume of ER suspension were measured every hour. A very small quantity of activated ER suspension, $0.1 \mathrm{~mL}$, was taken every hour and diluted with $500 \mathrm{~mL} n$-hexane solvent. One cc solution was re-taken from the diluted solution and rediluted with $100 \mathrm{~mL} n$-hexane solvent. The re-diluted solution was uniformly deposited to $0.47 \mu \mathrm{m}$ pore size membrane filter element for measuring average particle size and number distribution of dispersed particles. Average particle size and number distribution of activated particles deposited in membrane filter element were measured with an Image Analyzer System (Model Omnimet 2, UK) and the results are shown at Figures $1 \mathrm{a}$ and $1 \mathrm{~b}$. As seen in Figures 1 and 2, although the volume fraction of phosphoric ester cellulose particles was maintained constant, increasing activation time at $120^{\circ} \mathrm{C}$ increased average particle size and number distribution of dispersed particles per unit volume of ER suspensions till the activation time of $5 \mathrm{~h}$, when the increase was abruptly reduced. From Figure 2, activating of phosphoric ester cellulose ER suspensions was generated by swelling of phosphoric ester cellulose particles in silicone oil. After $5 \mathrm{~h}$, swelling by silicone oil was rapidly reduced. Thus, slow increase of average particle size and number distribution of dispersed phosphoric ester cellulose particles after $5 \mathrm{~h}$ was due to reduced swelling of phosphoric ester cellulose particles. 


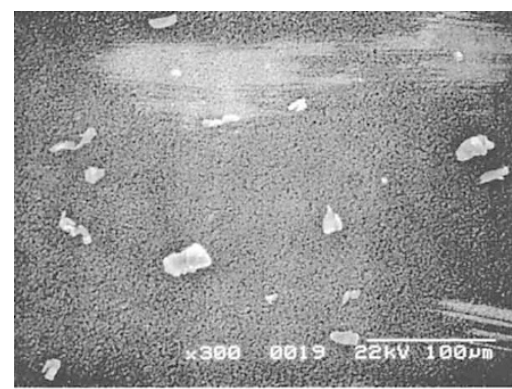

(a)

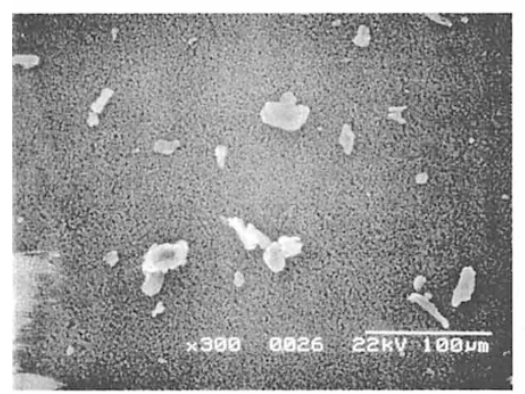

(c)

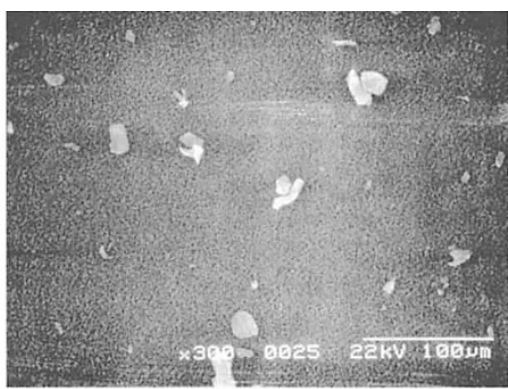

(b)

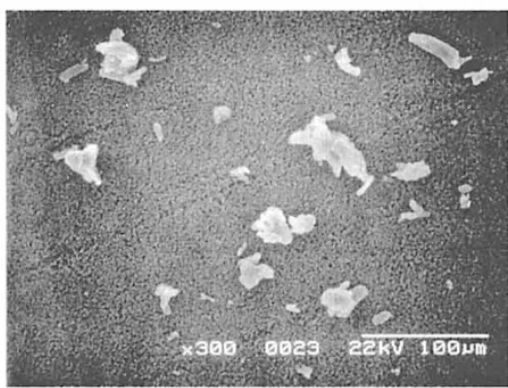

(d)

Figure 2. SEM of activated dispersing particles. (a) $0 \mathrm{~h}$, activation, (b) $3 \mathrm{~h}$, activation, (c) $5 \mathrm{~h}$, activation, and (d) $8 \mathrm{~h}$, activation.

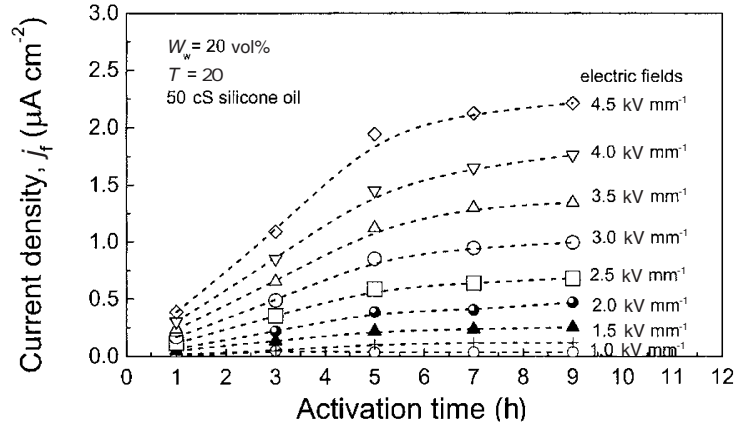

(a)

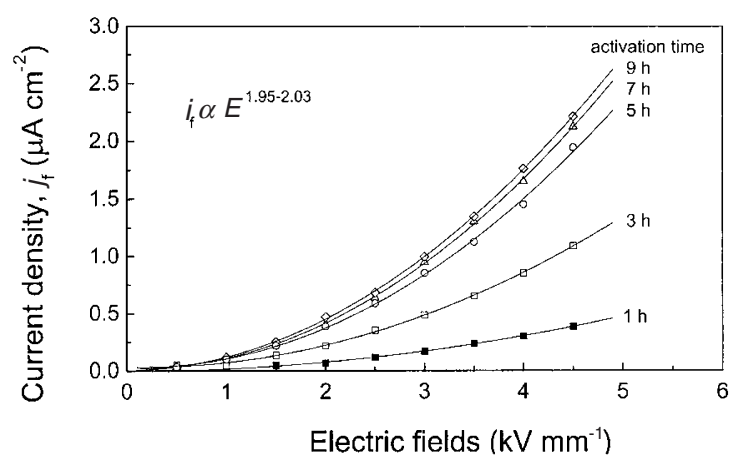

(b)

Figure 3. Current density of phosphoric ester cellulose ER suspensions on the various activation time and electric field. (a) Current density vs. Activation time. (b) Current density vs. Electric fields.

\section{Electrical Properties of Activated ER Suspensions}

The continuous phase of ER suspensions is a typically nonconductive and low dielectric constant oil.

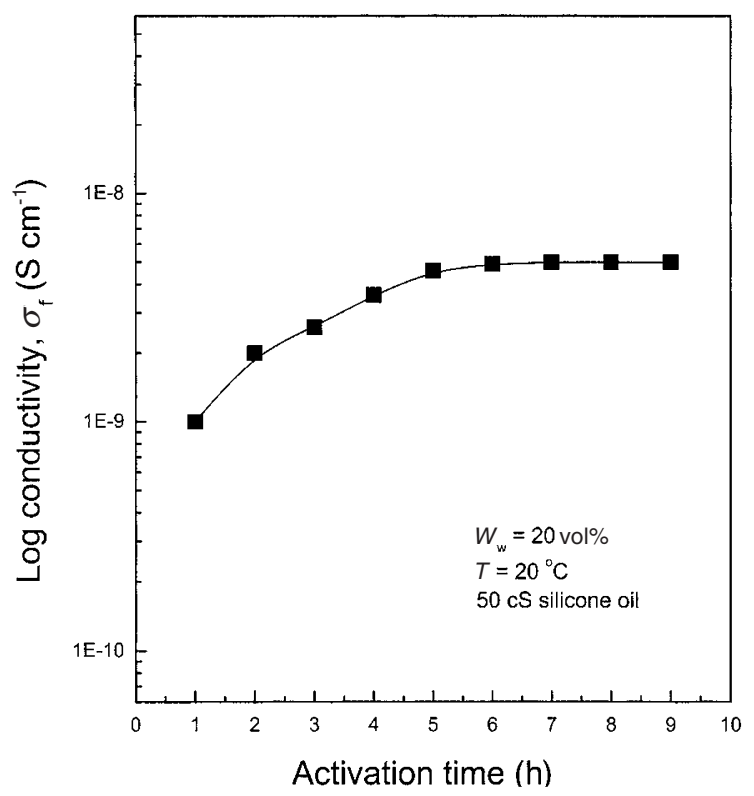

Figure 4. Electrical conductivity of phosphoric ester cellulose ER suspensions on activation time.

Current density and conductivity of phosphoric ester cellulose ER suspensions (Figures 3 and 4) were measured at room temperature. Volume fraction of phosphoric ester cellulose particles was maintained constant, but current density and conductivity of ER suspensions were changed with time. Current density increased with time at $120^{\circ} \mathrm{C}$, and was proportional to the electric field with the power law at constant volume fraction of dispersed particles. $\left(j_{\mathrm{f}} \propto E^{m}, m=1.95-\right.$ 2.03) 
As seen in Figure 4, increase of activation time increased conductivity under constant electric field within $5 \mathrm{~h}$ at $120^{\circ} \mathrm{C}$. Increase of conductivity was there after rapidly reduced, as in Figures $1 \mathrm{a}$ and $1 \mathrm{~b}$.

Conductivity of anhydrous ER suspensions based on phosphoric ester cellulose may thus be enhanced with time at $120^{\circ} \mathrm{C}$, and the best ER suspensions may be obtained by controlling activation time.

Assuming volume fraction $(\phi)$ small and absolute temperature $(T)$ and electric charge of insulation oil $\left(e_{0}\right)$ constant, the dielectric constant $(\Delta \varepsilon)$ of ER suspensions was found proportional to product of volume fraction $(\phi)$, radius of colloidal particles $(R)$ and surface charge density $\left(\sigma_{0}\right)$ in colloidal spherical particles. ${ }^{19}$

$$
\Delta \varepsilon \propto \phi \times R \times \sigma_{0}
$$

The dielectric behavior of phosphoric ester cellulose ER suspensions (constant volume fraction) with variation in activation time at $120^{\circ} \mathrm{C}$ is shown in Figure 5 . The dielectric constant of ER suspensions based on phosphoric ester cellulose particles increased for $5 \mathrm{~h}$ at constant volume fraction $(\phi)$, as also noted for current density (Figure 3), conductivity (Figure 4) and average particle size and number distribution of dispersed particles per unit volume of ER suspensions (Figure 1).

From Figures 1 and 5, the dielectric constant behavior of phosphoric ester cellulose ER suspensions is closely related to average particle size and number distribution of dispersed particles per unit volume of ER suspensions. Although volume fraction $(\phi)$ and surface charge density $\left(\sigma_{0}\right)$ is constant in eq 3 , dielectric constant $(\Delta \varepsilon)$ of ER suspensions increased with activation time at $120^{\circ} \mathrm{C}$. Activation time at $120^{\circ} \mathrm{C}$ is thus closely related to dispersed particles size $(R)$ and number, as also shown in Figure 2.

\section{Rheological Properties of Activated ER Suspensions}

Apparent viscosity $\left(\eta_{0}\right)$ without electric field, as shown in Figure 6, which had large influence on ER effect $\left(\eta_{\mathrm{R}}=\eta_{\mathrm{A}} / \eta_{0}\right.$ or $\left.\tau_{\mathrm{R}}=\tau_{\mathrm{A}} / \tau_{0}\right)$ was measured. Apparent viscosity behavior of phosphoric ester cellulose ER suspensions was noted for Newtonian fluids under without electric fields. When the volume fraction of phosphoric ester cellulose particles was maintained constant, $\eta_{0}$ increased with time at $120^{\circ} \mathrm{C}$ for more than $5 \mathrm{~h}$, as also shown in Figures 1 and 5. Apparent density of ER suspensions was closely related to the specific surface area of dispersed particles. Activating of ER suspensions at $120^{\circ} \mathrm{C}$ may increase the specific surface area of dispersed particles due to increased the average particle size and number distribution of them.

Dynamic yield stress of anhydrous ER suspensions dispersed phosphoric ester cellulose was proportional

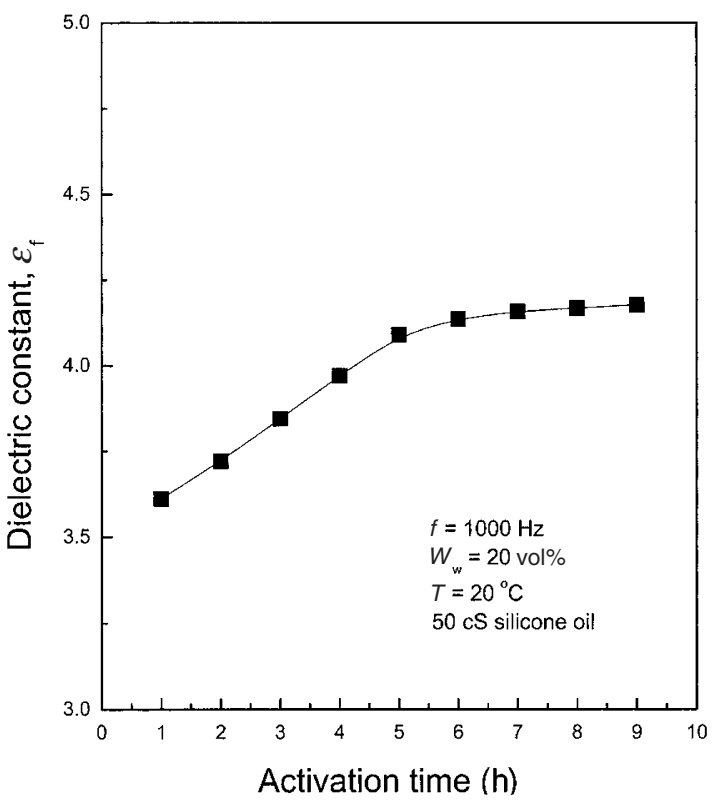

Figure 5. Correlation between dielectric constant and activation time of phosphoric ester cellulose ER suspensions.

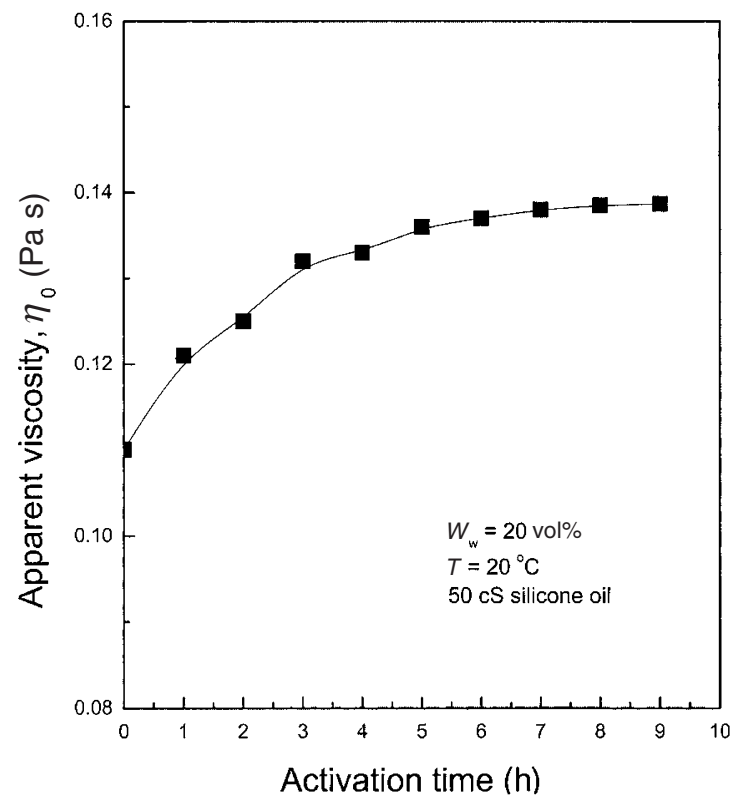

Figure 6. Apparent viscosity of phosphoric ester cellulose ER suspensions on activation time without an electric field.

to the electric field with the power law at constant volume fraction of dispersed particles. $\left(\tau_{\mathrm{y}} \propto E^{n}, n=1.84\right.$ 1.49) After $5 \mathrm{~h}, n$ approached 1.5.

As seen in Figure 8, dynamic yield stress increased with activation time under constant electric field but increase was abruptly reduced after $5 \mathrm{~h}$. Dynamic yield stress of anhydrous ER suspensions based on phosphoric ester cellulose is thus closely related to activation time at $120^{\circ} \mathrm{C}$. Dynamic yield stress of ER suspensions thus will increase with specific surface area of dispersed particles at constant volume fraction of particles. 


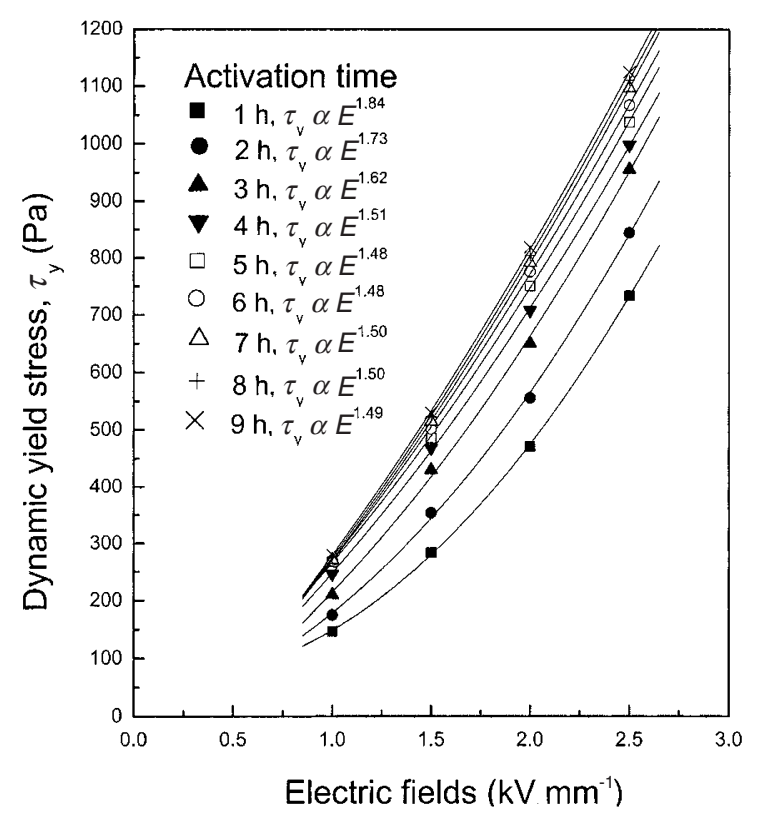

Figure 7. Correlation between dynamic yield stress and electric field on activation time. (20 vol\% in $50 \mathrm{cS}$ silicone oil, $\left.20^{\circ} \mathrm{C}\right)$

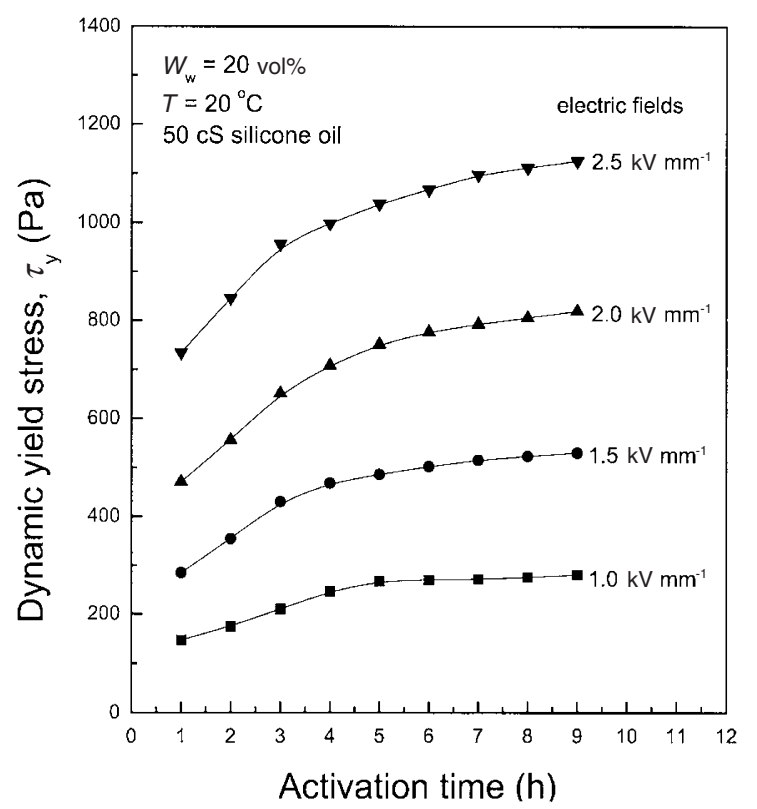

Figure 8. Correlation between dynamic yield stress and activation time on the electric field.

The correlation between ER effect $\left(\eta_{\mathrm{R}}\right.$ or $\tau_{\mathrm{R}}, \eta_{\mathrm{R}}=$ $\eta_{\mathrm{A}} / \eta_{0}$ or $\left.\tau_{\mathrm{R}}=\tau_{\mathrm{A}} / \tau_{0}\right)$ and activation time with variation in electric fields is shown in Figure 9 from which increase in ER effect of anhydrous ER suspensions based on phosphoric ester cellulose may occur at greater average particle size and number distribution of dispersed ER particles. Activation time of phosphoric ester cellulose ER suspensions was thus set at $5 \mathrm{~h}$ at $120^{\circ} \mathrm{C}$.

\section{CONCLUSIONS}

ER behavior, dielectric constant, current density,

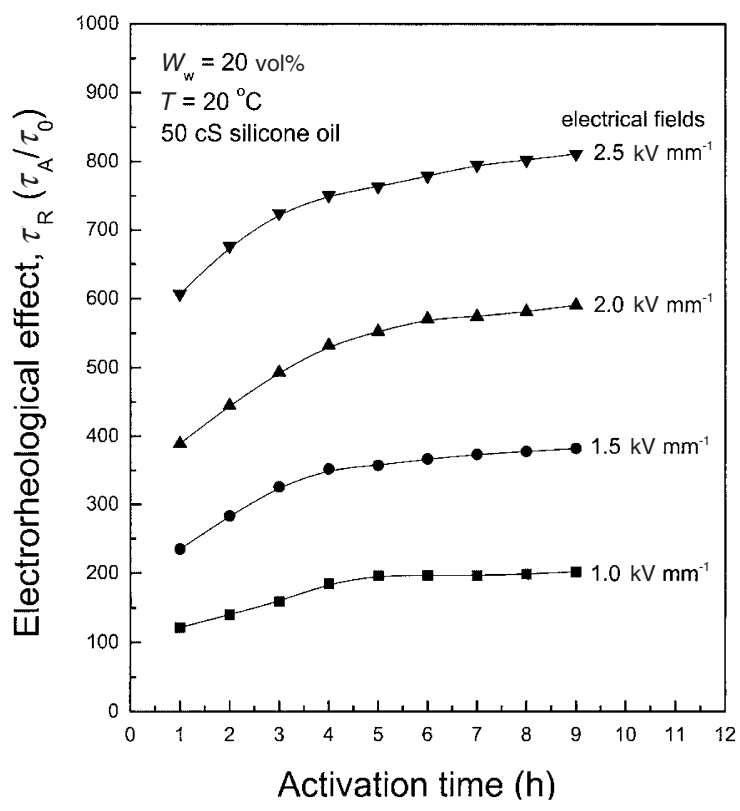

Figure 9. Correlation between electrorheological effect and activation time on electric field. ( shear rate $=100 \mathrm{~s}^{-1}$ )

electrical conductivity, and rheological properties, of activated anhydrous ER suspensions were studied. At constant volume fraction of phosphoric ester cellulose particles, increase in activation time at $120^{\circ} \mathrm{C}$ enhanced average particle size and number distribution of dispersed particles per unit volume in ER suspensions. Current density and conductivity of ER suspensions increased with time at $120^{\circ} \mathrm{C}$ and the best ER suspensions could be obtained by controlling activation time. Although volume fraction $(\phi)$ and surface charge density $\left(\sigma_{0}\right)$ of dispersed particles were constant, dielectric constant $(\Delta \varepsilon)$ of ER suspensions increased with time at $120^{\circ} \mathrm{C}$ and was closely related to dispersed particles size and number. Dynamic yield stress of anhydrous ER suspensions dispersed phosphoric ester cellulose particles was proportional to the electric field with the power law at constant volume fraction of dispersed particles. $\left(\tau_{\mathrm{y}} \propto E^{n}, n=1.84-1.49\right)$ After $5 \mathrm{~h}, n$ approached 1.5. For phosphoric ester cellulose ER suspensions, dynamic yield stress and electrorheological (ER) effect increased with the specific surface area of dispersed particles at constant volume fraction of dispersed particles and activation time of phosphoric ester cellulose particles in ER suspensions for increasing ER effect was $5 \mathrm{~h}$ at $120^{\circ} \mathrm{C}$.

\section{REFERENCES}

1. A. W. Duff, Phys. Rev, 23, 4 (1896).

2. W. M. Winslow, J. Phys., 1137, 20 (1949).

3. Z. P. Shulman, R. G. Gorodkin, E. K. Koroboko, and V. K. Gleb, J. Non-Newtonian Fluid Mech., 29, 8 (1981).

4. D. Scott and J. Yamaguchi, Automot. Eng., 61, 91 (1983). 
5. T. G. Duclos, D. N. Acker, and J. D. Carson, Machine Design, 2, 42, (1998).

6. J. E. Stangroom, U. S. Patent 4493615 (1985).

7. D. Scott and J. Yamaguchi, Automot. Eng., 75, 93 (1985).

8. I. F. Anaskin, V. K. Gleb, E. V. Korobko, B. P. Khizhinskii, and B. M. Khusid, J. Eng. Phys., 233, 42 (1984).

9. T. G. Duclos, "An Externally Tunable Hydraulic Mount which Use Electro-rheological Fluid”, Soc. Automotive Eng. Tech. Paper Ser. 1988, No. 870963, pp 131-137.

10. T. G. Duclos, "Design of Devices Using Electrorheological Fluids", Soc. Automotive Eng. Tech. Paper Ser., 1988, No. 881134, pp 1-5.

11. J. E. Stangroom, Brit. Patent 1570234 (Nov. 26, 1980).
12. J. W. Westhaver, U. S. Patent 3970573 (July 20, 1976).

13. K. Takeo and Y. Omura, U. S. Patent 3984339 (Oct. 5, 1976).

14. P. M. Adriani and A. P. Gast, Phys. Fluids, 2757, 31 (1988).

15. B. G. Ahn, U. S. Choi, and O. K. Kwon, Polym. J., 494, 31 (1999).

16. H. Conrad, A. F. Sprecher, Y. Choi, and Y. Chen, J. Rheol., 1393, 35 (1991).

17. C. Wu and H. Conrad, J. Phys. D : Appl. Phys., 3147, 29 (1996).

18. B. G. Ahn, U. S. Choi, and O. K. Kwon, Polym. J., 476, 32 (2000).

19. G. Schwarz, J. Phys. Chem., 2636, 66 (1962). 